\title{
Multiwalled Carbon Nanotube-titania Nanocomposites: Understanding Nano-Structural Parameters and Functionality in Dye-sensitized Solar Cells
}

\author{
Edwin T. Mombeshora ${ }^{a}$, Reuben Simoyi ${ }^{\mathrm{a}}$, Vincent O. Nyamori and Patrick G. Ndungu ${ }^{\mathrm{b}, \star}$ \\ ${ }^{a}$ School Chemistry and Physics, University of KwaZulu-Natal, Westville Campus, Private Bag X54001, Durban, 4000, South Africa. \\ ${ }^{b}$ Department of Applied Chemistry, University of Johannesburg, P.O. Box 17011, Doornfontein, Johannesburg, 2028, South Africa.
}

Received 18 September 2014, revised 26 April 2015, accepted \& 7 May 2015.

\begin{abstract}
Nanocomposites consisting of multiwalled carbon nanotubes and titania were synthesized by two methods, namely, sol-gel and chemical vapour deposition (CVD) methods. The work takes advantage of the bridging ability of nanotechnology between macromolecules and the solid state process in engineering alternative nanomaterials for various applications including solar cell fabrication. Physical and chemical characterization of the mesoporous nanocomposites from the two synthetic methods were investigated using Raman spectroscopy, thermogravimetric analysis, Fourier transformation infrared spectroscopy, scanning electron microscopy, transmission electron microscopy, high-resolution transmission electron microscopy, surface characterization and X-ray diffraction analysis. Physicochemical properties in the nanocomposites such as thermal stability, pore volume, crystallinity and surface area were observed to be a subject of MWCNT: titania ratios and synthetic methods. From the CVD synthetic method, observed attributes include more uniform and smoother coating; better crystallinity and larger pore width than sol-gel method. On the other hand, nanocomposites from sol-gel synthetic method had larger surface areas, were more defective and less thermally stable than those from CVD. Nanocomposites by the CVD method performed $39.2 \%$ more efficient than those from sol-gel in light-harvesting experiments. The study shows that the nanocomposites synthesized were more effective than titania alone when the cheaper natural dye, Eosin B, was used. This highlights the great potential of typical nanomaterials in improving the performances of titania in DSSCs as well as lowering the cost of the ultimate devices.
\end{abstract}

KEYWORDS

Dye-sensitized solar cells, multiwalled carbon nanotubes, nanocomposite, titania, sol-gel, chemical vapour deposition.

\section{Introduction}

In terms of clean and renewable energy, dye-sensitized solar cells (DSSCs) offer an interesting and attractive alternative to the various options available, especially for a developing world economy. DSSCs are relatively simple systems that can be assembled with minimal amounts of inexpensive materials, operate under varying light conditions and temperatures, can be assembled or moulded into various shapes, configurations, and colours. ${ }^{1}$ DSSCs are photo-electrochemical systems that use a dye to capture energy from sunlight, transfer this to a metal oxide such as zinc oxide ${ }^{1,2}$ or titania, ${ }^{1-3}$ and eventually via several physical-chemical processes provide a usable current. Titania is the most widely used metal oxide in DSSCs and is the one component in the system that is widely studied to try to improve overall performance of DSSCs. ${ }^{1}$

Titania is a highly versatile material for nanoscience and nano-technological-based applications. It is a material with relatively low toxicity, is widely available, has a well-known band gap, and is easily synthesized into various rationally designed morphological forms with desirable physico-chemical properties. These factors are some of the reasons why titania has been used in various applications such as biomorphic ceramics, ${ }^{4}$ sensors, ${ }^{5}$ photocatalytic applications such as water purification reactions, ${ }^{6,7}$ electro-catalysis, ${ }^{8}$ as columns in phosphopeptides analysis ${ }^{9}$ and in DSSCs. ${ }^{2,10}$

* To whom correspondence should be addressed. E-mail: pndungu@uj.ac.za
A growing area of research is the combination of titania with carbon nanostructures, such as carbon nanotubes (CNTs). Nanocomposites of titania are nano-scale multiphase materials, ${ }^{11}$ and titania $\mathrm{CNT}\left(\mathrm{TiO}_{2} / \mathrm{CNT}\right)$ nanocomposites have been shown to have an improved efficiency when compared to bare titania, in various applications. Some of the reasons for the improvement in performance include superior characteristics regarding separation of charge carriers within the nanocomposite, ${ }^{12}$ excellent electrical conductivity, and a relatively large surface area for physico-chemical processes. Several examples that utilize $\mathrm{TiO}_{2} / \mathrm{CNT}$ nanocomposites have been reported in literature, and these include research on photo-catalysis, ${ }^{13-19}$ electrochemical energy conversion ${ }^{20}$ and storage, ${ }^{21}$ and dye-sensitized solar cells. ${ }^{10,14,22,23}$

Carbon nanotubes can be simply described as a rolled up sheet of graphene, and based on the number of sheets they can be classified as single, double, and multiwalled CNTs. ${ }^{3}$ Multiwalled CNT (MWCNTs) are relatively easy to synthesize via the chemical vapour deposition method, and manipulation, purification, and modification can be accomplished using various methods in a moderately equipped laboratory ${ }^{24}$. Use of MWCNTs in DSSCs is an active area of research, and early work in this field used MWCNTs in DSSCs as either a counter electrode ${ }^{25}$ an additive, ${ }^{26}$ or as a nanocomposite material. ${ }^{27-29}$

MWCNT-titania nanocomposites have been fabricated by a number of ways such as sol-gel, ${ }^{30}$ mechanical mixing, ${ }^{10}$ electro- 
spinning, ${ }^{14,23}$ electrophoresis deposition, ${ }^{31}$ novel surfactant solgel wrapping ${ }^{18}$ blending ${ }^{13}$ physical vapour deposition, sputtering deposition, ${ }^{16}$ supercritical fluid deposition, ${ }^{19}$ capillary action, hydrothermal ${ }^{32}$ and chemical vapour deposition (CVD). ${ }^{33}$ MWCNTs agglomerate easily and extra care must be taken to ensure that the nanotubes disperse homogeneously within a matrix of interest. In MWCNT-titania nanocomposites, poor dispersability and agglomeration of precursors during synthesis can reduce the physico-chemical performance of the materials. Surfactants are one option that is commonly used to try to reduce such effects. ${ }^{34}$

The objectives of this study were to elucidate trends in physicochemical properties as MWCNTs: titania wt.\% ratios vary, investigate how synthetic methods employed affect nanocomposite physical properties, and the light-harvesting characteristics in a DSSC using either Eosin B or N3-dye. This work compares typical effects of MWCNT-titania nanocomposites synthesized by sol-gel and CVD methods as well as their suitability in low cost natural dye-based solar cells. DSSCs are simple to fabricate and are a clean form of renewable energy. ${ }^{35}$ This study also highlights the importance of various aspects like morphological orientations of titania and MWCNTs in addition to reduction of electron-hole recombination with increase in MWCNT ratio. In short, this report provides a deeper understanding of the typical characteristics influencing ultimate efficiencies of MWCNT-titania nanocomposites in light-harvesting applications.

\section{Experimental}

\subsection{Materials}

MWCNTs, $\sim 95 \%$, were purchased from Cheaptubes.com (MA, USA), and the listed properties were 8-15 $\mathrm{nm}$ OD, length $10-50 \mu \mathrm{m}$, Ash $<1.5 \mathrm{wt} . \%$, SSA $\bullet 233 \mathrm{~m}^{2} \mathrm{~g}^{-1}$, EC $\bullet 10^{-2} \mathrm{~S} \mathrm{~cm}^{-1}$, (SKU number 030102). Reagents used were: concentrated sulfuric acid - $98 \%$ to $100 \%$ (AAR) and hydrochloric acid $\geq 32 \%$ (SMM Instruments, Midrand, South Africa), nitric acid $\geq 69 \%$, titanium(IV)isopropoxide and titanium(IV) methoxide - $95 \%$ (Sigma-Aldrich, Pty. Ltd. Johannesburg, South Africa) and ethanol $-99.7 \%$ to $100 \%$ ( Analar R, BDH chemicals Ltd., England).

\subsection{Method}

The acid treatment method for MWCNTs was modified from the work reported by Liu et al..$^{21} \mathrm{In}$ this study, $\mathrm{HCl}$ substituted $\mathrm{H}_{2} \mathrm{SO}_{4}$ and other alterations are as explained below. MWCNTs $(1 \mathrm{~g})$ were acid-treated in a mixture of $\mathrm{HNO}_{3} / \mathrm{HCl}$ at 3:1 (v/v) ratio, respectively, in an ultrasonic water bath. The mixture was treated for $4 \mathrm{~h}$ and thereafter the MWCNTs were washed with distilled water until the filtrate had a neutral $\mathrm{pH}$. MWCNTs were then dried at $120^{\circ} \mathrm{C}$ using an Economy Series, Model 220-224 ovens supplied by Scientific Ltd. and stored in a desiccator.

The general procedure used with the sol-gel method involved adding a predetermined mass of MWCNTs in $30 \mathrm{~mL}$ ethanol and treating the mixture in an ultrasonic water bath for $10 \mathrm{~min}$. This was then followed by adding a known concentration of titanium isopropoxide (TIP) that had been previously mixed in $10 \mathrm{~mL}$ ethanol. The mixture was further ultrasonic-treated for $30 \mathrm{~min}$, stirred for about $30 \mathrm{~min}$ and thereafter left in open air overnight to dry. The sample was then dried and calcined at $400{ }^{\circ} \mathrm{C}$ for $4 \mathrm{~h}$ in an open furnace.

The cylindrical metal-organic chemical vapour deposition (MOCVD) reactor was constructed with commercially available stainless steel parts, which were purchased from Swagelok (Swagelok, Durban, South Africa). The bottom of the reactor was made of Swagelok face seal fitting cap (part number SS-8-VCR-CP). The reactor consisted of a cylindrical stainless steel reaction chamber body made from 316/316L SS seamless tubing (part number SS-T8-S-035-6ME) sealed at one end (bottom) with a Swagelok face seal fitting with a blind gasket. The top consisted of various Swagelok parts (part numbers SS-8-VCR-6-810, SS-8-VCR-3-8TA, SS-810-6-4, and SS-8-VCR-1) and an angle valve (part number: SS-42GS4-A). VCR face seal fitting, and a silver-plated filter gasket, non-retained style, 0.5 micron (part number SS-8-VCR-2-5M) was fitted to minimize loss of sample and contamination of the whole system connected to a vacuum pump. The vacuum line was constructed from 316/316L SS seamless tubing, (part number SS-T4-S-035-6ME). Valves were included in the system by use of SS 1-piece 40 series angle pattern ball valves, (part number SS-42GS4-A). A VCR face seal fitting female nut (part number SS-8-VCR-1) was used to seal the VCR fittings and SS Swagelok tube fitting, and a reducer (part number SS-810-6-4) was used to connect the fitting to the tubing coming from the valve. A thyracont VD84/1 Pirani vacuum gauge was used to measure absolute pressure.

For the CVD synthetic method, a predetermined mass of MWCNTs was mechanically mixed with a known mass of titanium(IV) methoxide using a pestle and mortar. The mixture was loaded into a MOCVD reactor and the reactor was then inserted into a horizontally-aligned Economy Series tube furnace; Model 220-224 ovens (supplied by Scientific Ltd.). The MOCVD reactor was then connected to vacuum pump and evacuated to a pressure of approximately $1 \times 10^{-2} \mathrm{mbar}$, and then the furnace was ramped up to a temperature of $100{ }^{\circ} \mathrm{C}$ to eliminate water vapour. After $60 \mathrm{~min}$, the temperature was increased to $400^{\circ} \mathrm{C}$ at $2{ }^{\circ} \mathrm{C} \mathrm{min}^{-1}$. The vacuum pump was turned off during the heating phase between $100{ }^{\circ} \mathrm{C}$ and $400{ }^{\circ} \mathrm{C}$. The maximum heating temperature was kept at $400^{\circ} \mathrm{C}$ since anatase phase of titanium is stable at that temperature. Nanocomposites were thereafter physico-chemically characterized and applied in lightharvesting experiments. In light-harvesting experiments; nanocomposites/ethanol mixture was treated in an ultrasonic water bath prior to deposition onto ITO coated glass using a doctor blade method, ${ }^{36}$ a gel state electrolyte reported elsewhere ${ }^{37}$ was used as the redox material, the counter electrode was aluminium (with a film thickness of $0.608 \mathrm{~K} \AA$ ) coated on ordinary glass. Eosin $\mathrm{B}$ was the sensitizing dye.

For fabrication of DSSCs, nanocomposites (100 mg) were added to ethanol $(0.3 \mathrm{~mL})$. The mixture was treated for at least $20 \mathrm{~min}$ in an ultrasonic water bath. Nanocomposites dispersed in ethanol were thereafter deposited onto ITO-coated glass using the doctor blade method.$^{38}$ This photoanode electrode was then sintered at $300{ }^{\circ} \mathrm{C}$ for $30 \mathrm{~min}$ on a hot plate. Eosin B dye $(150 \mu \mathrm{L})$ was added using a micropipette onto the anode electrode. Plasticine was placed on either side of the deposited nanocomposite to prevent the electrolyte from flowing outside the active area. The electrolyte used was an iodine-based gel state electrolyte. ${ }^{39}$ Aluminium was then used as the counter electrode and the thickness of aluminium deposited on the glass was noted as $0.608 \mathrm{~K} \AA$. The device was made with the aluminiumcoated glass side facing the dye-stained nanocomposite to make a sandwiched device. The counter electrode was then connected to the cathode terminal and nanocomposite to the anode before illumination by 1 sun $\left(100 \mathrm{~mW} \mathrm{~cm}^{-2}\right)$ via the nanocomposite side. For comparative purposes, similar devices were constructed using cis-bis(isothiocyanato)bis(2,2'-bipyridyl-4,4'-dicarboxylato)ruthenium(II) dye and nanocomposites that had the comparable optimum performance with the Eosin B dye. 


\subsection{Characterization}

A Delta Nu Advantage 532 spectrometer was used for Raman spectroscopy analysis of the nanocomposites. The detector employed was a 2D CCD type and grating lines were 1800 per $\mathrm{mm}$. Resolution was $10 \mathrm{~cm}^{-1}$. Excitation wavelength of the laser was $532 \mathrm{~nm}$ and laser power rating was $100 \mathrm{~mW}$. Integration time was $35 \mathrm{~s}$ and resolution was high (as indicated by the software). Data analysis from Raman spectroscopy was done by peak fitting using the Lorenztian function.

The XRD analysis was done using the D8 Advance diffractometer supplied by BRUKER AXS, Germany. Measurements were done with $\theta-\theta$ scan in locked coupled mode, tube details were $\mathrm{Cu}-\mathrm{K} \alpha$ radiation $\left(\lambda \mathrm{K} \alpha_{1}=1.5406 \AA\right)$ and detectors used were PSD Vantec-1. The instrument software was from International Centre for Diffraction Data (ICDD), data base for 1998 and EVA software from BRUKER was used for data evaluation.

Thermal stability analysis was done using TA Instruments Q series ${ }^{\mathrm{TM}}$ Thermal Analyzer DSC/TGA (Q600). TA instruments Universal Analysis 2000 software was used for thermogram analysis and data acquisition.

A high-resolution transmission electron microscopy (HRTEM) instrument was carried out in a JEOL JEM 2100 with an accelerating voltage of $100 \mathrm{kV}$.

For FTIR analysis, samples were pelletized in $\mathrm{KBr}$. This was done using a 25-ton ring press (00-25 model supplied by Research Industrial Company, England). In a typical experiment, $\mathrm{KBr}(5 \mathrm{~g})$ was mixed with MWCNT-titania nanocomposite $(0.01 \mathrm{~g})$ prior to making a pellet using the mixture $(0.15 \mathrm{~g})$ and the pressure applied was 10 ton. The disk was taken into a Perkin Elmer FTIR spectrometer (spectrum RXI, version 5.3) for analysis.

Textural characteristics were done by weighing masses of nanocomposites into a tube then degassed at $90^{\circ} \mathrm{C}$ for $1 \mathrm{~h}$ and thereafter at $160{ }^{\circ} \mathrm{C}$ overnight. The nanocomposites were accurately reweighed after degassing. The textural analyses were done by using a Micromeritics TRI STAR 3020V1.03 (V1.03) instrument at $77 \mathrm{~K}$ in $\mathrm{N}_{2}$.

Diffuse reflectance was done using a HR2000 ${ }^{+}$model High Resolution spectrometer. The light source was halogen HL-2000-FHSA supplied by Narich with a spectra suite software. A T300-RT-UV-Vis EOS 1212277 optical fibre was used. Ten scans were averaged, box width was five and integration time was $15 \mathrm{~ms}$. The data were fitted using a Kubelka-Munk function.

Light-harvesting measurements were done using a solar simulator supplied by Keithley Instruments ${ }^{\mathrm{TM}}$ USA, (model SS50AAA) with a xenon short AKC $150 \mathrm{~W}$ lamp, light source was steady state (shutter controlled), air mass (AM) was $1.5 \mathrm{G}$, voltage was $116-220 \mathrm{v}$, frequency was $50-60 \mathrm{~Hz}$ and maximum power was $750 \mathrm{~W}$.

Photoluminescence (PL) was done using a Perkin Elmer LS35 fluorescence spectrometer. A front surface accessory LS55 model solid probe was used since the nanocomposites were in a solid state. Excitation was done at $300 \mathrm{~nm}$, spectrum range from 350 to $550 \mathrm{~nm}$, excitation slit was $5 \mathrm{~nm}$, emission slit was $0 \mathrm{~nm}$ and scan speed was $120 \mathrm{~nm} \mathrm{~min}^{-1}$. The software used for data acquisition was FL Winlab version 4.00.03 Perkin Elmer Inc.

\section{Results and Discussion}

\subsection{SEM Investigations}

Figure 1 presents SEM images on 5,10, 20 and $50 \mathrm{wt}$.\% samples prepared using the CVD (left column) and the sol-gel (right column) methods. The selected samples are presented to highlight general trends with the various samples prepared. With the CVD and sol-gel methods there is a similar change in the distri- bution of the titania deposits within the CNT powders. In general at low loadings the titania partially covers individual CNTs and this increases with the change in loading until the maximum loading of $50 \mathrm{wt}$.\% results in complete coverage of individual CNTs.

With the CVD method (Fig. 1a, b, c, d), besides changes noted with the titania coverage on individual nanotubes, the various samples showed presence of large agglomerates with varying irregular shapes or with aspect ratios that suggest the titania had covered the CNT bundles. In contrast, the sol-gel method had slightly fewer loose titania agglomerates. During the sol-gel process, titania nucleation and growth, via a hydrolysis mechanism, will occur on the surface acid sites located along the sidewalls of the CNTs. $22,27,29,30$

With the sol-gel method the CNTs were subjected to an ultrasound treatment before and right after mixing with the titania precursor. Thus,some of the nanotubes were detached from the CNT bundles and as a result there were a greater number of nucleation sites for the growth of titania deposits which can account for the slightly fewer titania agglomerates observed with the sol-gel method.

\subsection{TEM Observations}

At all loadings studied, titania deposits that coated individual CNTs or loose agglomerates were observed. Representative TEM images are shown in Fig. 2. The images were similar to those observed by Gao et al. ${ }^{34}$ The titania nanoparticle size on MWCNTs was measured using image J software.

The slight difference in sizes between the CVD and sol-gel methods can be attributed to changes in the nucleation and growth of the titania coatings with the respective methods. As noted with SEM observations, the sol-gel method allowed for a greater number of nucleation sites which can influence the final particle size.

\subsection{Functional Groups and Bonding within Nanocomposites}

FTIR was used to investigate functional groups and bonding between components in nanocomposite. A number of interesting peaks were observed, and a representative spectrum is presented in Fig. 3 with the scale adjusted to emphasize the peaks identified. The peak at $1627 \mathrm{~cm}^{-1}$ after acid treatment is due to the presence of oxygen-containing groups, i.e. $\mathrm{C}-\mathrm{O}, \mathrm{COO}$ and $\mathrm{C}=\mathrm{O}^{40,41}$ introduced onto the sidewalls of MWCNT during the treatment, while new peaks appearing at $2327 \mathrm{~cm}^{-1}$ and $2329 \mathrm{~cm}^{-1}$ are assigned to hydrogen bonding due to the $\mathrm{COOH}$ groups present. $^{22,42}$

The peak at $3427 \mathrm{~cm}^{-1}$, which appeared in all nanocomposites after addition of titania, is assigned to carbonyl and/or O-H bonds associated with hydroxyl groups. ${ }^{42-45}$ The peak at $2920 \mathrm{~cm}^{-1}$ is assigned to a C-H bond within the MWCNT sample. ${ }^{46} \mathrm{~A}$ low intensity peak at $1103 \mathrm{~cm}^{-1}$ representing Ti-O-C bond assigned to a covalent link between titania and $\mathrm{MWCNTs}^{47}$ was observed in the nanocomposites produced by both synthetic methods. In both synthetic methods, new peaks appeared at approximately 600,577 and $411 \mathrm{~cm}^{-1}$, and these peaks were assigned to the anatase phase of titania. ${ }^{15,47}$

\subsection{Raman Spectroscopic Analysis}

Raman analysis of carbon nanotubes monitors peaks such as radial breathing mode due to the innermost tube diameter of MWCNTs, ${ }^{48}$ the G-band due to the tangential in-plane C-C stretching vibrations, ${ }^{46}$ Raman allowed phonon mode $\left(\mathrm{E}_{2(\mathrm{~g})}\right)^{49}$ the $\mathrm{D}$-band which is due to the $\mathrm{A}_{(\mathrm{g} 1)}$ mode $\mathrm{e}^{50}$ and $2 \mathrm{D}$ band which is the first overtone of the D- and the G-bands. ${ }^{51}$ For each 

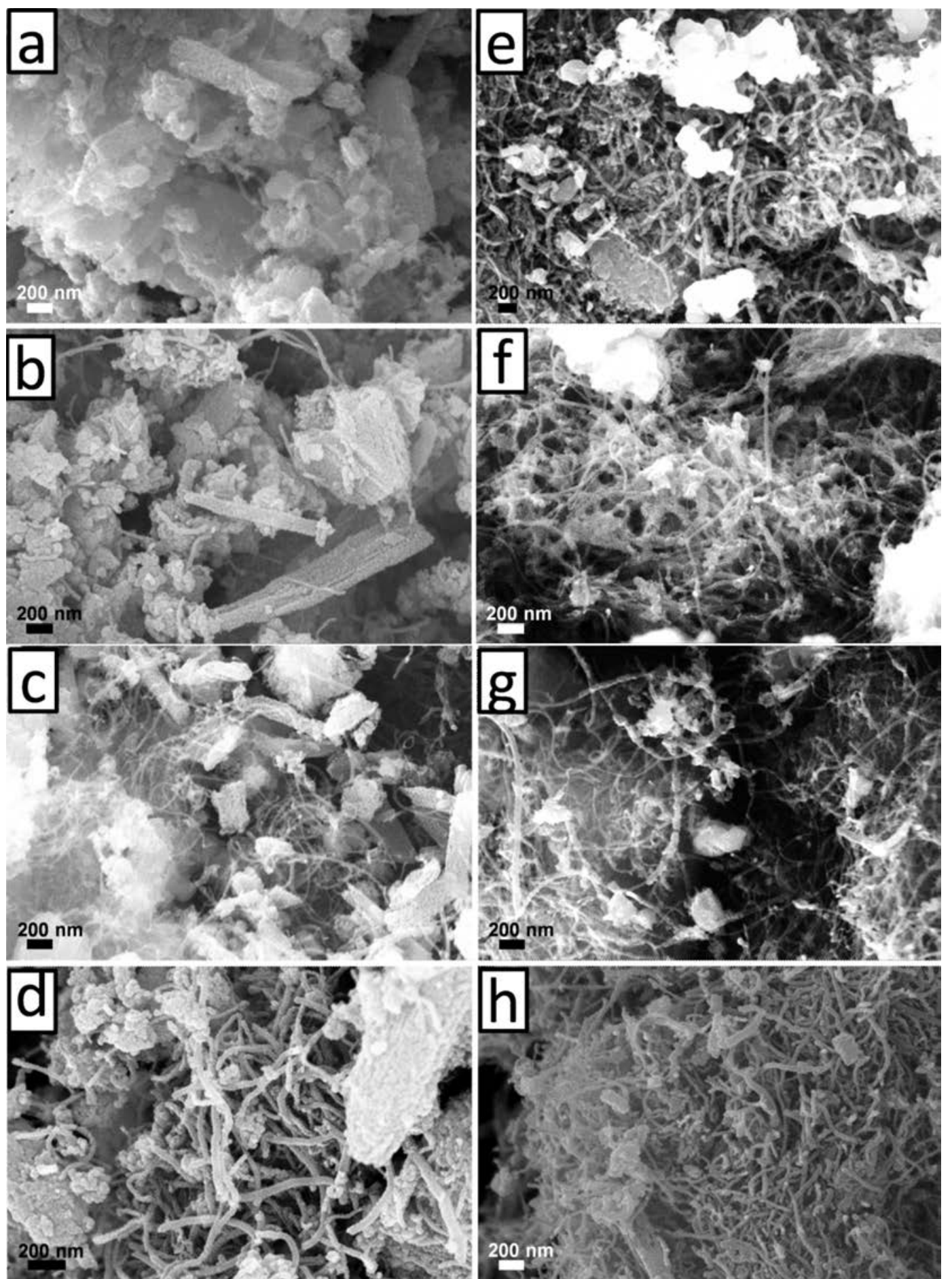

Figure 1 The left column (panels $\mathbf{a}, \mathbf{b}, \mathbf{c}, \mathbf{d}$ ) presents SEM images of samples synthesized using the CVD method, with target loadings of 5, 10, 20 and $50 \mathrm{wt} . \%$, respectively. The right column (panels $\mathbf{e}, \mathbf{f}, \mathbf{g}, \mathbf{h}$ ) presents SEM images of samples synthesized using the sol-gel method with target loadings of $5,10,20, \& 50 \mathrm{wt} . \%$, respectively.

nanocomposite an average of three spectra were used and the Dand the G-bands were fitted using a Lorenztian function. The $\mathrm{I}_{\mathrm{D}} / \mathrm{I}_{\mathrm{G}}$ ratios were thereafter calculated from the ratio of integrated intensity of the D- and G- bands. The $\mathrm{I}_{\mathrm{D}} / \mathrm{I}_{\mathrm{G}}$ ratios generally increased and then later decreased with various wt.\% used (Table 1) with both CVD and sol-gel methods. The $\mathrm{I}_{\mathrm{D}} / \mathrm{I}_{\mathrm{G}}$ ratios provide information on the extent of structural defects on the sidewalls of the carbon nanotubes. ${ }^{46}$ Both methods gave an increase in the $\mathrm{I}_{\mathrm{D}} / \mathrm{I}_{\mathrm{G}}$ ratios at $50 \mathrm{wt}$.\% of MWCNTs probably due to the number defects on MWCNT walls and the amount of titania available to cover the defect sites. Furthermore, both methods have a low $\mathrm{I}_{\mathrm{D}} / \mathrm{I}_{\mathrm{G}}$ ratio at $5 \mathrm{wt}$. \%, which is likely due to the low amount of nanotubes, and the large amount of titania that can bind and cover the defect sites. Hwang et al. ${ }^{25}$ suggested that the oxygen-containing groups introduced onto MWCNTs during acid purification can act as nucleation sites for the formation of titania. The presence of the Ti-O-C bond in the FTIR spectra (Fig. 3) is an indication that the titania is located at defect sites and bonds to the oxygen containing group on the sidewalls of the nanotubes. An increase in the $\mathrm{I}_{\mathrm{D}} / \mathrm{I}_{\mathrm{G}}$ ratio from 5-10 wt.\% can be attributed to increased amount of nanotubes, and thus more defect sites available; however, the 

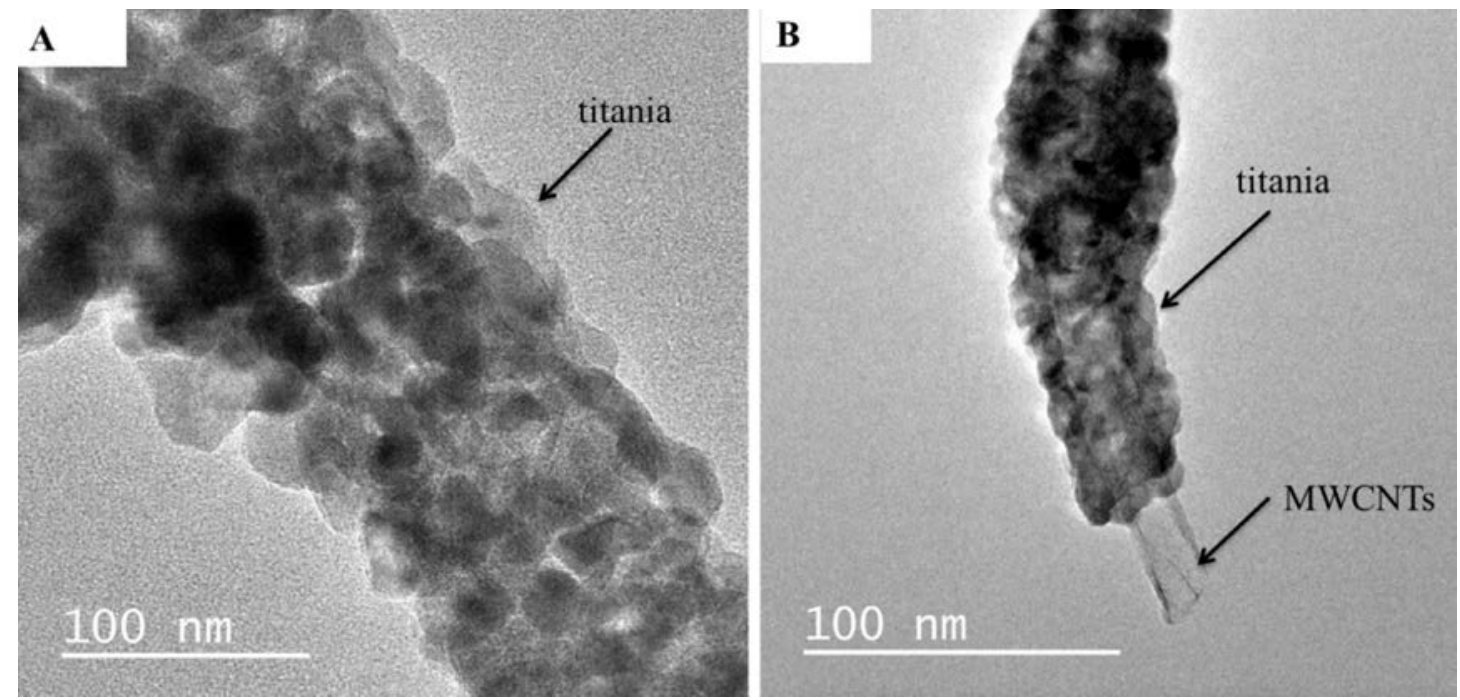

Figure 2 HRTEM images for MWCNT-titania nanocomposites at $10 \mathrm{wt}$ \% of MWCNTs for (A) CVD and (B) sol-gel methods

decrease from 10-20 wt.\% (both methods) maybe due to an offset in terms of titania binding to the oxygen groups within the defect sites.

At lower wavenumbers, the Raman spectra for the nanocomposites synthesized using the sol-gel method showed peaks at around 425, 548, and $638 \mathrm{~cm}^{-1}$. The CVD method had similar peaks at 396, 518, and $600 \mathrm{~cm}^{-1}$. These peaks are assigned to the vibrational modes of the B1g, (A1g + B1g) and Eg symmetry modes in titania. ${ }^{10,15,23,52}$ The difference in the peak positions suggests a stronger interaction between the titania and the CNTs with the sol-gel samples compared to the CVD samples.

\subsection{XRD Results}

Figure 4 presents typical XRD patterns for the nanocomposites, and all the peaks fitted the anatase phase of titania. Miller indices observed were similar from both synthetic methods, and were assigned to $101,200,105,211,204,166,220$ reflections at $2 \theta$ of 37.8 , $48.1,54,55.1,62.8,68.8$ and $70.3^{\circ}$, respectively. There were no rutile phases observed, and these results agreed with the FTIR and Raman results, and shows that both methods produced only the anatase phase of titania.

The peaks for the MWCNTs could not be clearly identified, since the main peak for MWCNTs at around $26^{\circ} 2 \theta$, overlaps with the main titania peak, and thus would be obscured by the titania peak. In addition, the loading of MWCNTs, and the higher crystallinity of the titania would contribute to the masking of the MWCNT peaks. Similar observations have been made in the literature. ${ }^{10,23,52}$ It is interesting to note that the $10 \mathrm{wt} . \%$ nanocomposites produced using the CVD method had XRD patterns with sharper and more intense peaks when compared to the samples synthesized using the sol-gel methods (Fig. 4b). This suggests that the nanocomposites produced by the CVD method were more crystalline than those from the sol-gel method, at low wt.\% of MWCNTs. This may have been due to the heat treatment involved during the CVD synthesis method. Another possibility contributing to the difference in

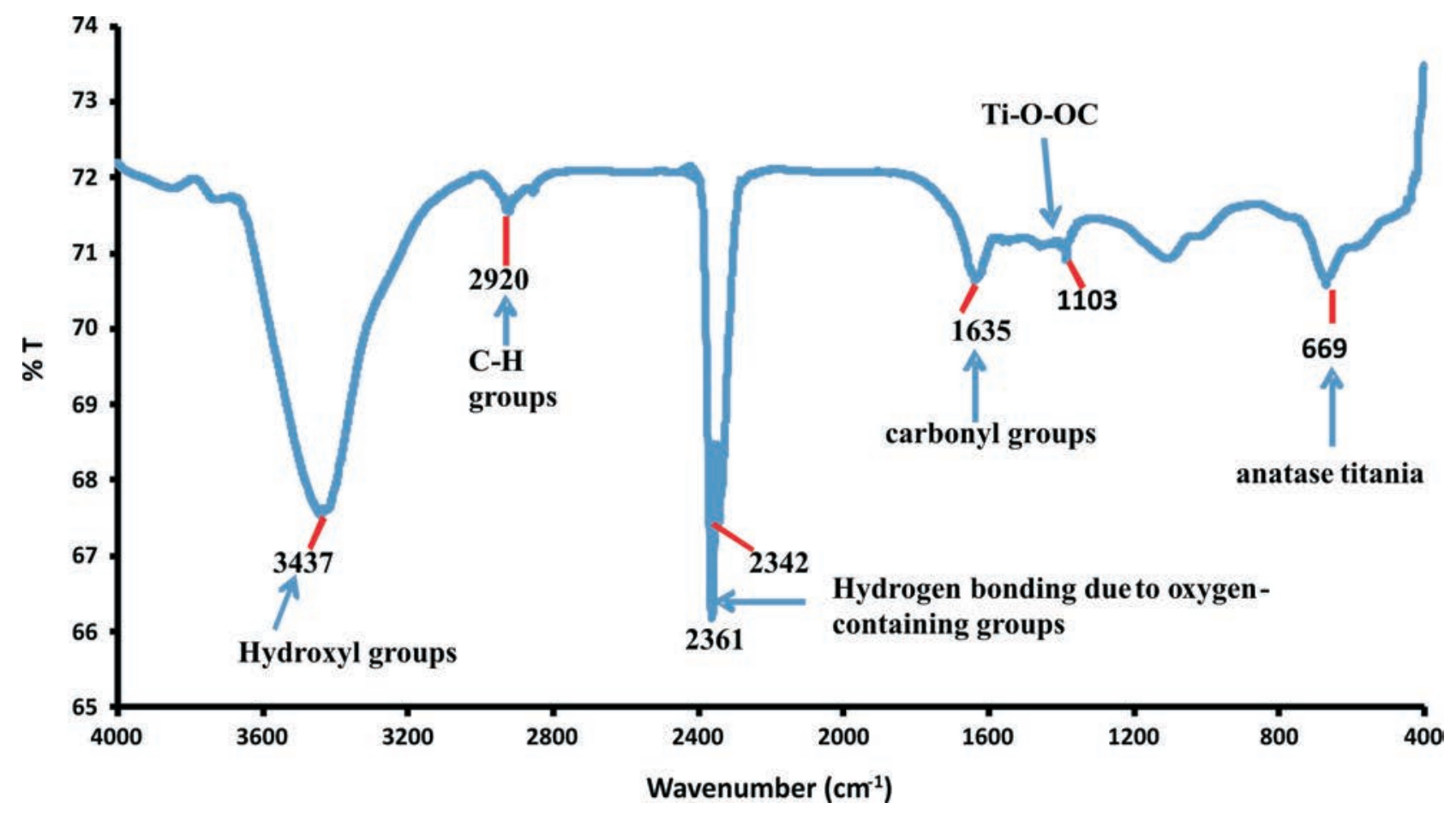

Figure 3 Typical FTIR spectra observed with the MWCNT-titania nanocomposites. The spectra is for the sol-gel $20 \mathrm{wt}$. $\%$ sample 
Table 1 Raman data for the nanocomposites synthesized using CVD and sol-gel methods.

\begin{tabular}{|c|c|c|c|c|c|c|}
\hline \multirow[t]{2}{*}{ Synthesis method } & \multirow[t]{2}{*}{ Wt. $\%$} & \multicolumn{2}{|c|}{$\mathrm{D}$ band } & \multicolumn{2}{|c|}{ G band } & \multirow[t]{2}{*}{$\mathrm{I}_{\mathrm{D}} / \mathrm{I}_{\mathrm{G}}$} \\
\hline & & Position $/ \mathrm{cm}^{-1}$ & FWHM & Position $/ \mathrm{cm}^{-1}$ & FWHM & \\
\hline \multirow[t]{4}{*}{ CVD } & 5 & 1332 & 52 & 1590 & 48 & 0.45 \\
\hline & 10 & 1327 & 68 & 1604 & 41 & 0.79 \\
\hline & 0 & 1350 & 53 & 1593 & 60 & 0.69 \\
\hline & 50 & 1348 & 52 & 1590 & 63 & 0.85 \\
\hline \multirow[t]{4}{*}{ Sol-gel } & 5 & 1356 & 42 & 1578 & 44 & 0.44 \\
\hline & 10 & 1351 & 53 & 1587 & 57 & 1.10 \\
\hline & 20 & 1355 & 107 & 1584 & 74 & 0.83 \\
\hline & 50 & 1352 & 69 & 1588 & 72 & 0.98 \\
\hline
\end{tabular}

intensities can be attributed to the larger amount of separate titania agglomerates observed, using SEM, with the CVD samples. SEM observations showed that the CVD method produced a lot more separate agglomerates of titania when compared to the sol-gel produced samples. Thus the greater intensity could be a contribution from the greater amount of titania agglomerates that are not coating the nanotubes within the CVD samples.

Using the Scherrer equation on the 200 reflection at $2 \theta$ of $48.1^{\circ}$, the average crystallite size for the titania deposits were calculated and the results are presented in Table 2 .

The compositional variation causes variations in concentration gradients which in turn influences d spacing, crystallite domain sizes and lattice strain. Also, titania nanoparticle size, except at 20 wt.\% of MWCNTs by sol-gel, generally decrease with increase in MWCNTs ratio. This is an indication of transition from bulk to nano scale on increase in MWCNTs ratio in the nanocomposites. ${ }^{51}$ This could be due to the fact that the larger surface area of nanotubes, due to the increased mass of nanotubes, provides a greater number of nucleation sites for the titania to deposit. This in turn would result in smaller titania particles.

\subsection{Surface Area and Porosity of the Nanocomposites}

The nitrogen sorption isotherms at $77 \mathrm{~K}$ for the CVD and sol-gel synthesized samples are presented in Fig. 5. The 5 wt.\% sample using the sol-gel method had no hysteresis loop (Fig. 5a). This implies that the small addition of MWCNTs had little effect on the porosity of the sample.

In contrast, the 5 wt.\% with the CVD method (Fig. 5b) has an H3-type hysteresis and a type IV isotherm, as per the IUPAC classification. ${ }^{53}$ This suggests the CVD sample has more porosity than the sol-gel sample. At higher loadings all samples show a type IV isotherm with an $\mathrm{H} 3$ hysteresis, indicative of mesoporous materials.

Table 2 presents data on the textural properties obtained from the analysis of the nitrogen sorption isotherms. The surface area of nanocomposites produced using the CVD method increased with MWCNTs wt.\% and, in general, a similar trend was observed with the sol-gel, except for the $20 \mathrm{wt}$.\% sample, which showed a drop from the $10 \mathrm{wt} . \%$ sample.

The drop in the pore volume and surface area, when comparing acid washed MWCNTs and the $5 \mathrm{wt}$.\% samples are due to the small amount of nanotubes in the samples and the blocking of the tips of the nanotubes by the titania. However, with the CVD sample, an increase in the pore size suggests a significant contribution from pores between agglomerates and not the openings from the nanotubes. The larger surface area with the sol-gel samples, when compared to the corresponding CVD samples can be attributed to the sonication method used during the sol-gel process. In addition, the smaller number of agglomer-

Table 2 Crystallite size of titania calculated from Scherrer equation using the peak at $48.12 \theta$.

\begin{tabular}{l|cc|cc|cc|cc}
\hline Sample & \multicolumn{2}{|c|}{5 wt. $\%$} & \multicolumn{2}{c|}{10 wt. $\%$} & \multicolumn{2}{c|}{20 wt. $\%$} & 50 wt. $\%$ \\
\hline Synthesis method & CVD & Sol-gel & CVD & Sol-gel & CVD & Sol-gel & CVD & Sol-gel \\
Crystallite size (nm) & 21.98 & 11.78 & 19.55 & 4.17 & 16.31 & 20.61 & 9.09 & 2.67 \\
\hline
\end{tabular}
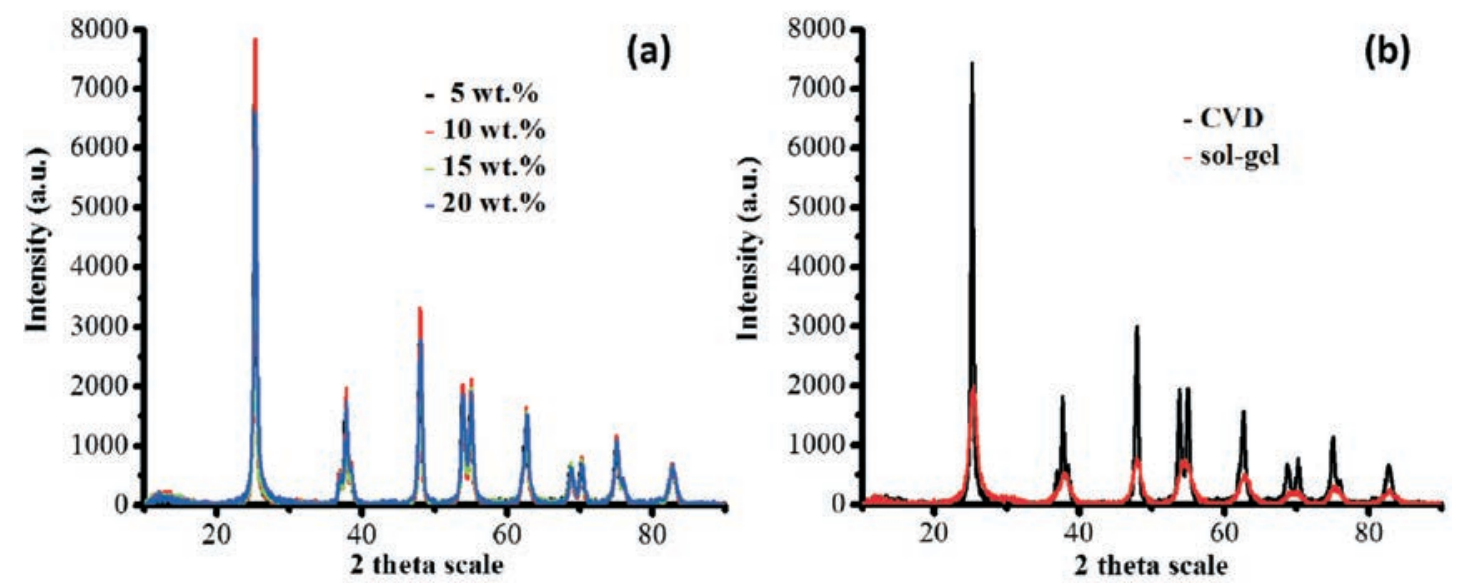

Figure 4 Representative powder XRD patterns for nanocomposites synthesized using the CVD method (a) and a comparison of XRD patterns for $10 \mathrm{wt}$ \% samples synthesized by the CVD and sol-gel methods (b). 

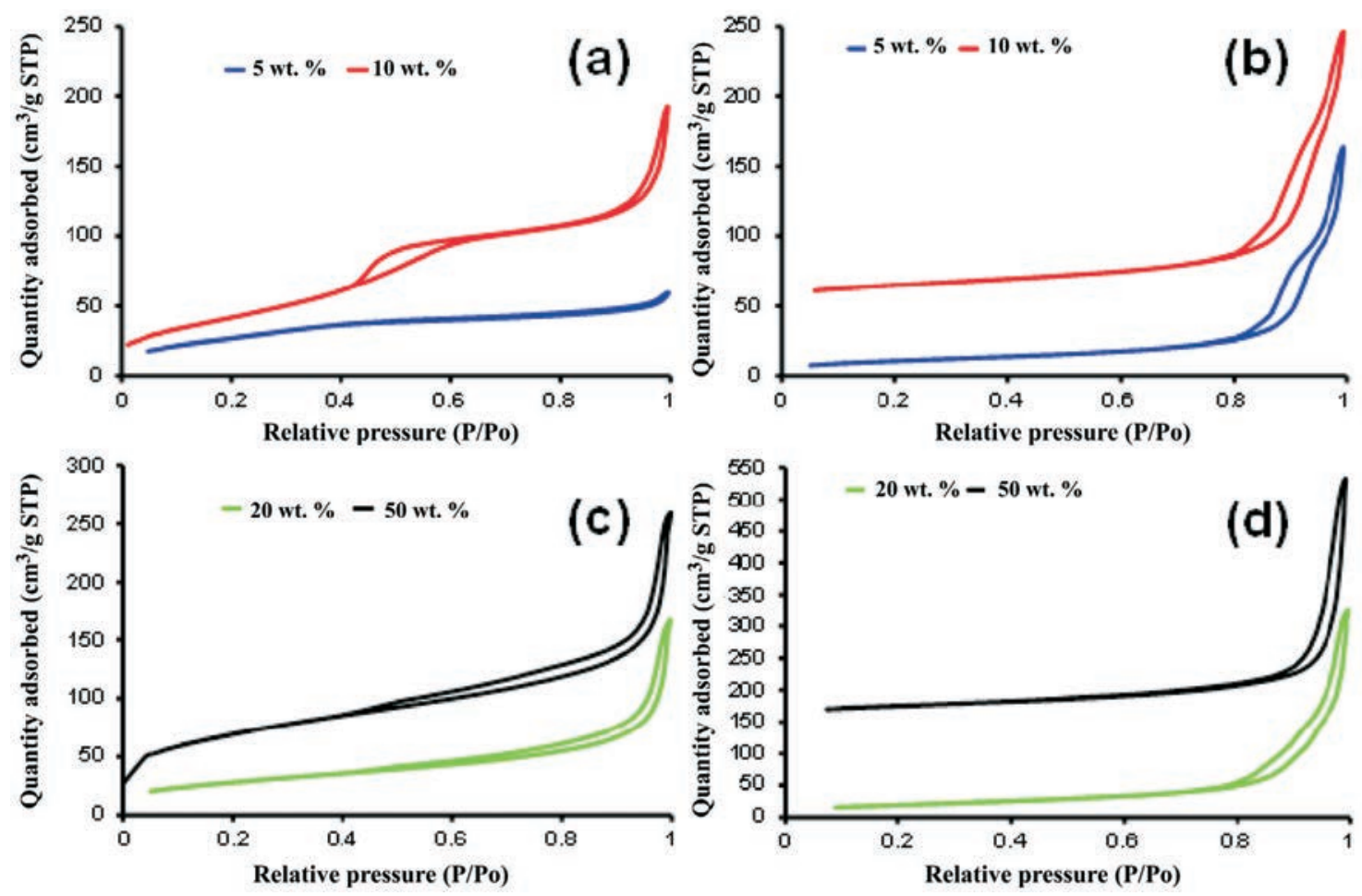

Figure 5 Nitrogen adsorption isotherms for the nanocomposites synthesized using the sol-gel method (a, c), and samples synthesized using the CVD method (b, d). The isotherms for the $10 \mathrm{wt}$.\% sample in (b) and the $50 \mathrm{wt} . \%$ sample in (d) were plotted with a small offset.

ates and fewer nanotube bundles observed with the sol-gel samples on the SEM, account for the higher surface areas measured with the volumetric gas analysis technique.

The surface area and porosity of the material used to sorb the dye molecules play an important role in DSSCs, since a large surface area improves the sunlight-dye interaction by exposing more dye molecules to incoming light. However, if some of the porosity is contributing to the surface area of the material, it may result in some of the dye sorbing to surfaces that do not contribute to the functioning of the DSSCs, for example the inner channels of the nanotubes.

\subsection{Thermal Stability}

The TGA data confirmed the loading of the MWCNTs within the samples, with the mass lost similar to the target values of 5, 10, 20 and 50 wt.\% (Fig. 6). The thermal stability of the samples was determined from the point of maximum weight loss using the derivative of the weight loss curve, and results are presented in Fig. 6. The CVD samples had their oxidation temperature reduced from $683.7,635.5,630.6$, and $549.0^{\circ} \mathrm{C}$ with the $5,10,20$ and 50 wt. $\%$ samples, respectively. At 5 wt.\% loading, the nanotubes are fully covered by the titania and from the FTIR results the titania covers the defect sites. As a result, the high oxidation temperature is likely due to a limited amount of exposed nanotube surfaces or defect sites. Defect sites decrease the oxidation temperature of $\mathrm{CNTs},{ }^{42}$ thus as the loading of nanotubes increases, there is a larger amount of nanotube surface exposed and thus more defect sites exposed, and as a result this leads to a decrease in the oxidation temperature.

From the Raman analysis, the $\mathrm{I}_{\mathrm{D}} / \mathrm{I}_{\mathrm{G}}$ ratio for the $5 \mathrm{wt}$.\% CVD and sol-gel samples were similar, indicating a relatively lower density of defect sites, and hence the largest oxidation temperature. The trend with the oxidation temperature and the increasing $I_{D} / I_{G}$ ratio for the CVD samples supports the assertion that the changes in exposed nanotube surfaces and defect sites can account for the TGA observations.
In contrast, the sol-gel samples oxidation temperature changes from $607.5,558.5,596.9$, and $554.7^{\circ} \mathrm{C}$ for the $5,10,20$ and 50 wt. $\%$ samples, respectively. Heating nanotubes in air can induce defect sites onto the walls of CNT walls. Thus, the lower oxidation temperature, when compared to the CVD samples, can be attributed to the calcination procedure in static air with the sol-gel samples.

\subsection{Photoluminescence}

Photoluminescence with titania nanomaterials originates from the recombination of electrons and holes at trap sites located at non-coordinated Ti sites or oxygen vacancies. ${ }^{38}$ MWCNTs have been shown to reduce recombination rates by effectively capturing and transporting generated electrons from the titania and thus reducing recombination with generated holes. ${ }^{33,54}$ From Fig. 7, the increase of the ratio of MWCNTs with the Ti nanocomposites reduced the intensity of the PL signal from titania, which clearly indicated a reduction in the recombination rate.

From Fig. 7, there are two peaks that are due to the recombination of electrons and holes on trap sites within the titania, these are a broad peaks centred on $400 \mathrm{~nm}$, and a sharp peak at approximately $500 \mathrm{~nm}$. With the increased loading, the peaks are suppressed and not completely eliminated at the maximum loading of MWCNTs (50 wt.\%). The decrease in the intensity of the PL spectra indicated direct contact and interaction between the MWCNTs and the titania, possibly through the Ti-O-C bond (observed with the FTIR spectra). Zhao et al. ${ }^{39}$ made similar observations and showed that physical mixtures of CNTs and titania do not result in a significant decrease in the PL spectra.

\subsection{Application of Nanocomposites in Dye-sensitized Solar Cells}

Nanocomposites were then applied in DSSCs. The currentvoltage measurements were done by the use of a solar simulator. 

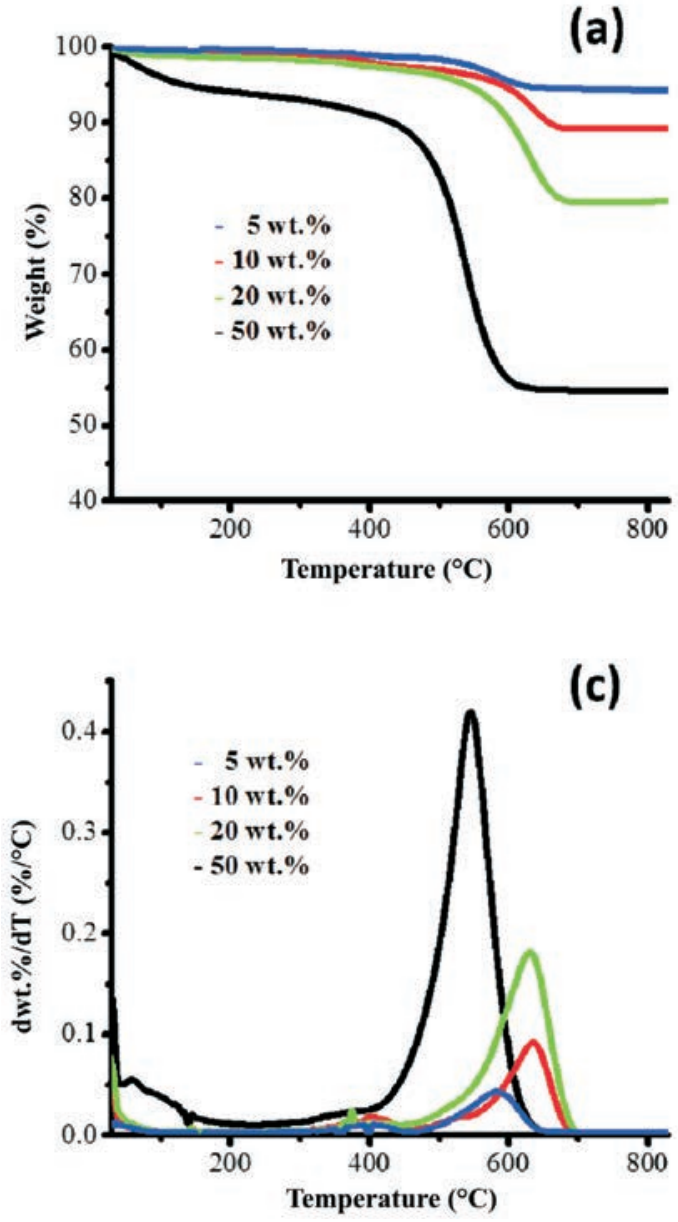
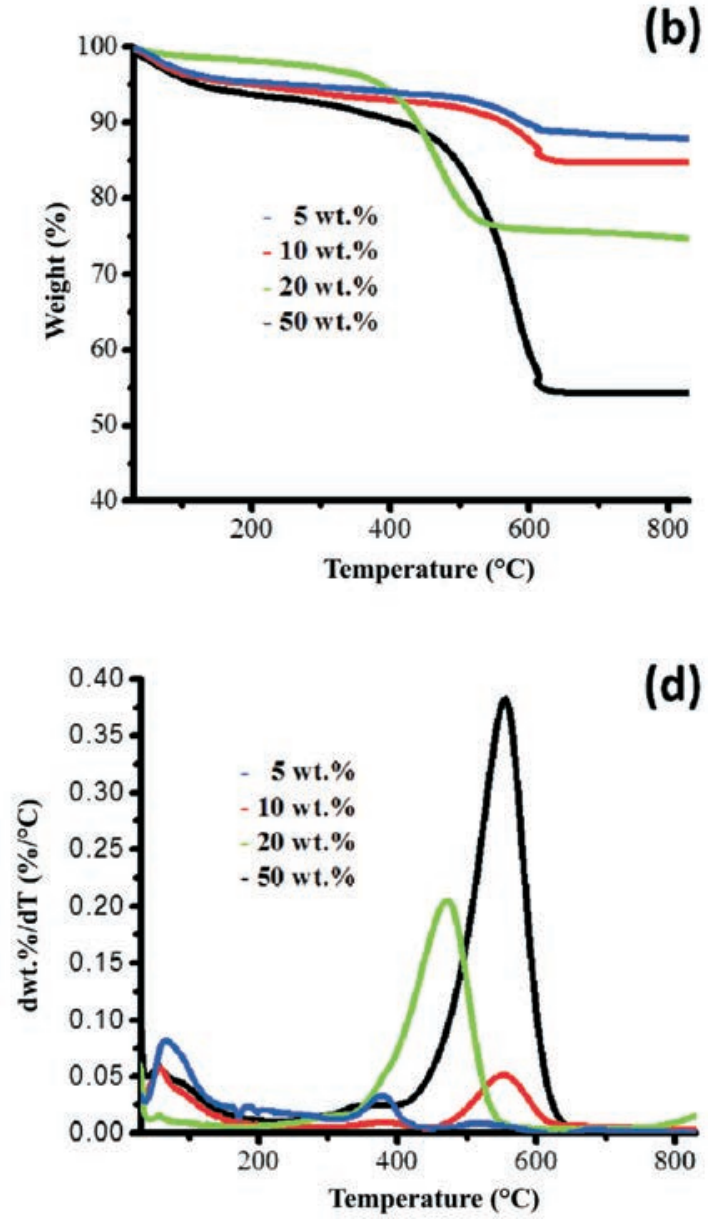

Figure 6 Thermal stability comparison for $\operatorname{CVD}(\mathbf{a}, \mathbf{c})$ and sol-gel methods $(\mathbf{b}, \mathbf{d})$.

The efficiency, $n$, was calculated according to Equation $1:^{2}$

$$
\mathrm{n}=\frac{\mathrm{FF} \times \mathrm{J}_{\mathrm{SC}} \times \mathrm{V}_{\mathrm{OC}}}{\text { Total insolation }}
$$

where $F F, J_{\mathrm{sc}}$ and $\mathrm{V}_{\text {oc }}$ are the fill factor, current density and open circuit voltage, respectively. ${ }^{1-3}$ The total insolation is given by the product of incident light per unit area and total area. Several devices were assembled from each sample and two experiments were done per device and the best data were recorded and presented in Table 4. Addition of MWCNTs to titania increased $\mathrm{V}_{\mathrm{OC}}$ at all wt.\% except at $20 \%$, for both methods (Table 4). $\mathrm{J}_{\mathrm{SC}}$ increased at all MWCNTs loadings except at $50 \mathrm{wt} . \%$ by the sol-gel method. The principal reason is the reduction in electron-hole recombination of titania as shown by PL results (Fig. 7). The 5, 10 and 15 wt.\% of MWCNTs had better efficiencies than titania on its own. At 5 wt.\% loading, nanocomposites synthesized using the CVD method gave larger $\mathrm{J}_{\mathrm{SC}}, \mathrm{V}_{\mathrm{OC}}$ values and higher efficiencies than the sol-gel method samples, although FF was lower for CVD (Table 3 ). The $\mathrm{I}_{\mathrm{D}} / \mathrm{I}_{\mathrm{G}}$ ratios were similar for the 5 wt.\% samples (thus surface trap sites, usually located at defect sites on the nanotubes) cannot account for the differences. The sol-gel samples have a smaller average crystallite size than the CVD samples (Table 2). Smaller grain boundaries in nanoparticulate films have been shown to hinder the transport of generated electrons and may act as trap sites. ${ }^{55}$ Thus, the smaller titania crystallites and greater number of grain boundaries with the sol-gel sample are the main reason for the differences in performance with the $5 \mathrm{wt}$.\% samples.

A similar argument can be applied to the differences with the $10 \mathrm{wt}$ \% samples. However, the larger $\mathrm{I}_{\mathrm{D}} / \mathrm{I}_{\mathrm{G}}$ ratio with the $10 \mathrm{wt} . \%$ sol-gel sample may imply that the defects on the nanotubes may play a small role (via trapping electrons) in the poor performance of these nanocomposites.

The 20 and 50 wt.\% of MWCNTs doped samples did show poor performances, and this was mainly due to the devices showing ohmic $v s$ rectifying behaviour. The percolation of nanotubes was too high within the nanocomposites to provide a suitable com-

Table 3 Textural characteristics of nanocomposites synthesized by the sol-gel and CVD methods. Two measurements were carried out for each sample and the average was recorded.

\begin{tabular}{|c|c|c|c|c|c|c|}
\hline \multirow[t]{2}{*}{ MWCNTs Loading (wt.\%) } & \multicolumn{2}{|c|}{ Surface area $/ \mathrm{m}^{2} \mathrm{~g}^{-1}$} & \multicolumn{2}{|c|}{ Pore volume $/ \mathrm{cm}^{3} \mathrm{~g}^{-1}$} & \multicolumn{2}{|c|}{ Pore size/nm } \\
\hline & CVD & Sol-gel & CVD & Sol-gel & CVD & Sol-gel \\
\hline 100 (MWCNTs) & 143.15 & 143.15 & 0.50 & 0.50 & 13.98 & 13.98 \\
\hline 5 & 38.51 & 102.04 & 0.22 & 0.10 & 27.06 & 3.77 \\
\hline 10 & 60.40 & 157.06 & 0.30 & 0.26 & 23.49 & 6.50 \\
\hline 20 & 70.85 & 99.60 & 0.48 & 0.24 & 27.38 & 10.79 \\
\hline 50 & 88.23 & 242.35 & 0.51 & 0.36 & 26.55 & 7.25 \\
\hline
\end{tabular}



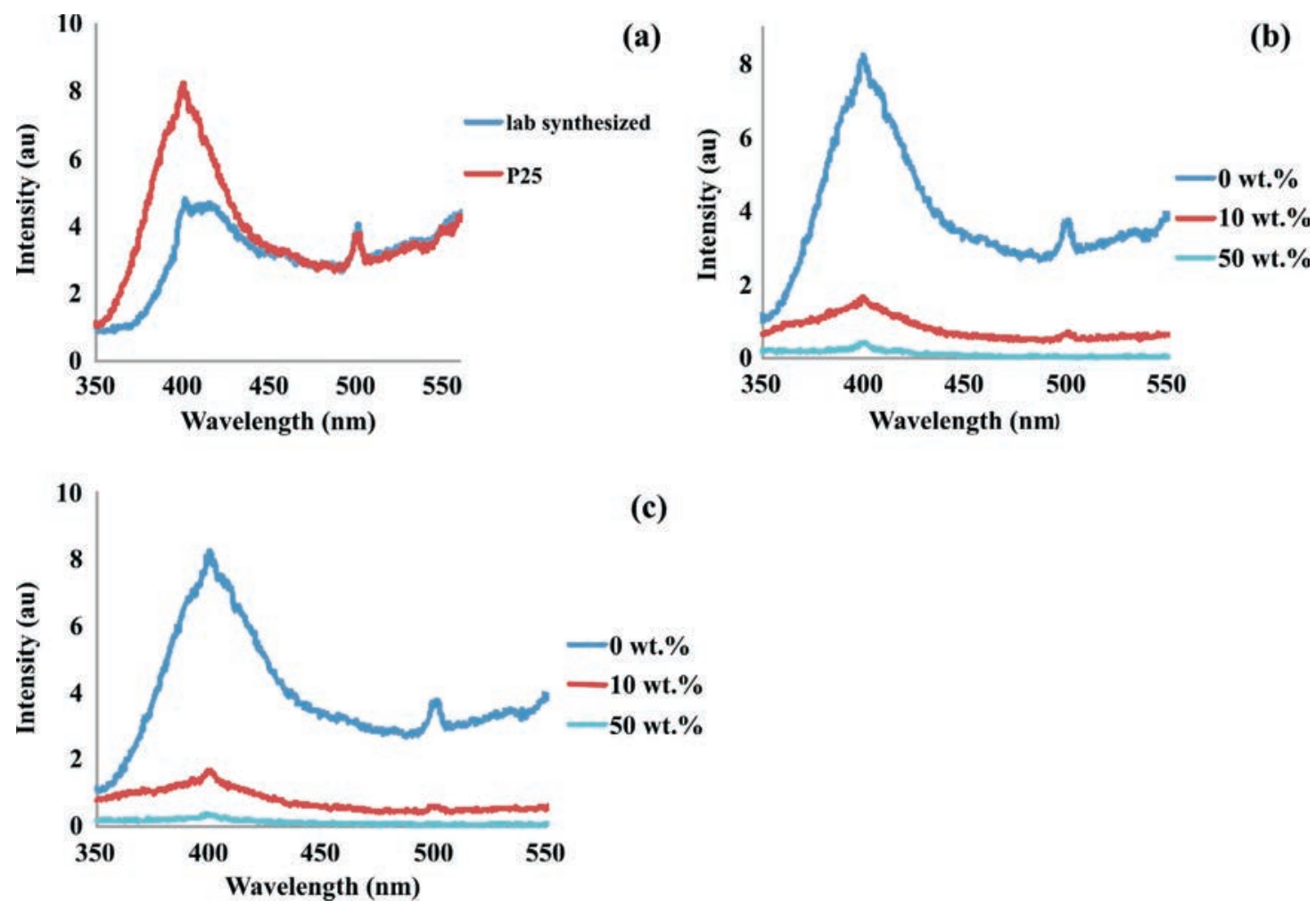

Figure 7 Photoluminescence spectra for (A) lab synthesized titania and commercial titania (P25) while (B) and (C) are nanocomposites synthesized using the CVD and sol-gel method, respectively. Excitation wavelength was $300 \mathrm{~nm}$

Table 4 Open circuit voltage $\left(\mathrm{V}_{\mathrm{OC}}\right)$, short circuit current $\left(\mathrm{J}_{\mathrm{SC}}\right)$, fill factor $(\mathrm{FF})$, and efficiency $(\eta)$ for the 5, 10, 20, and 50 wt.\% nanocomposites. Some examples from the literature are included for comparative purposes.

\begin{tabular}{|c|c|c|c|c|c|}
\hline MWCNTs wt.\% & Method & $\mathrm{V}_{\mathrm{OC}} / \mathrm{V}$ & $\mathrm{J}_{\mathrm{SC}} / \mathrm{m} \mathrm{A} \mathrm{cm}^{-2}$ & FF & $\eta$ \\
\hline 0 (titania) & N/A & 0.33 & 0.14 & 22.70 & 0.010 \\
\hline \multirow[t]{2}{*}{5} & CVD & 0.46 & 4.08 & 13.36 & 0.251 \\
\hline & Sol-gel & 0.66 & 1.76 & 11.66 & 0.135 \\
\hline \multirow[t]{2}{*}{10} & CVD & 0.65 & 2.56 & 63.76 & 1.061 \\
\hline & Sol-gel & 0.83 & 0.30 & 65.42 & 0.162 \\
\hline \multirow[t]{2}{*}{15} & CVD & 0.68 & 13.00 & 19.25 & 1.702 \\
\hline & Sol-gel & 0.59 & 0.40 & 43.20 & 0.102 \\
\hline \multirow[t]{2}{*}{20} & CVD & 0.04 & 2.08 & - & - \\
\hline & Sol-gel & 0.23 & 1.22 & 16.91 & 0.047 \\
\hline \multirow[t]{2}{*}{50} & CVD & 0.95 & 1.42 & 7.02 & 0.095 \\
\hline & Sol-gel & 0.68 & 0.01 & 33.99 & 0.002 \\
\hline 0.02 & Literature $^{1,10,39,40}$ & 0.65 & 8.88 & 53.00 & 3.05 \\
\hline 0.02 & & 0.79 & 12.00 & 59.00 & 5.63 \\
\hline 0.02 & & 0.82 & 11.98 & 62.00 & 6.12 \\
\hline 4 & & 0.64 & 11.52 & 66.00 & 4.89 \\
\hline
\end{tabular}

${ }^{*} \mathrm{~V}_{\mathrm{oc}}$ is open circuit voltage; ${ }^{*} \mathrm{~J}_{\mathrm{SC}}$ is short circuit current density; ${ }^{*} \mathrm{FF}$ is fill factor; ${ }^{*} \mathrm{n}$ is efficiency.

posite for DSSC application. This may be overcome with a suitable buffer layer within the device. Alternatively, 15 wt.\% samples were synthesized and tested in a DSSC device to test the limitations of the maximum amount of nanotubes within the current systems.

In terms of weight percentages, between 5-15 wt.\% loading, the best efficiency was observed with the CVD samples, most notably with the 15 wt.\% MWCNT loading. The highest $\mathrm{J}_{\mathrm{SC}}$ values were observed with the CVD samples, and the highest $\mathrm{V}_{\mathrm{OC}}$, with the exception of the $10 \mathrm{wt}$.\% samples, was observed with the CVD samples. The larger $\mathrm{J}_{\mathrm{SC}}$ values with the CVD samples implies an effective system for light harvesting and utilizing the extracted electrons, and can be attributed to the larger titania crystallites providing fewer trap states, and the presence of the nanotubes significantly reducing electron-hole recombination (PL spectra Fig. 7). However, both the sol-gel and CVD samples with the nanotubes will result in an enhanced $\mathrm{J}_{\mathrm{SC}}$ since the nanotubes effectively suppress electron-hole recombination, and can transport electrons efficiently. The key difference between the sol-gel and CVD samples is the distribution of the MWCNTs within the composites. SEM observations showed that the sol-gel method produces a more uniform distribution of CNTs with the titania matrix, and subsequent analysis revealed that the composites had higher surface areas, with 
Table 5 Comparison of Eosin B with cis-bis(isothiocyanato)bis(2,2'-bipyridyl-4,4'-dicarboxylato)ruthenium (II). Two experiments were carried out per device and the best data for each device fabricated are presented.

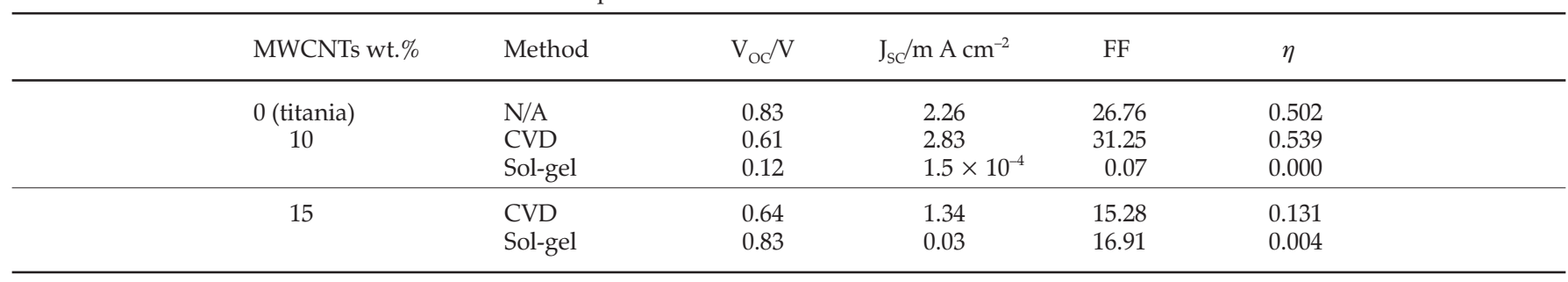

smaller titania crystallites, and generally higher defect density on MWCNTs. The enhanced $\mathrm{J}_{\mathrm{SC}}$ with the CVD samples is thus due to a relatively poor distribution of MWCNTs within the nanocomposites that allows for better extraction of the electrons. The larger titania crystallites and fewer defect sites resulted in a smaller number of trap sited for the charge carriers, which is more a significant factor than the lower surface area for absorption of the dye and capturing sunlight.

Overall the $\mathrm{V}_{\mathrm{OC}}$ within DSSCs is a function of the electrolyte, dye, and semiconductor film. Electron recombination/loss pathways such as the dye transferring electrons to the redox mediators instead of the semi-conductor, ineffective transfer of electrons from the redox mediator to the dye, and various interfacial resistances all contribute to lowering the $\mathrm{V}_{\mathrm{OC}}{ }^{1,3}$ The samples synthesized using the sol-gel method showed an increase in $\mathrm{V}_{\mathrm{OC}}$ from 5-10 wt.\% of MWCNTs doping, and this was directly related to the increase in surface area (Table 3). The increased surface area resulted in a larger and more effective distribution and layering of the dye molecules and therefore greater photo-conversion. In addition, the increase in MWCNT loading decreases recombination rates, and improves the device conductivity. The decrease with $\mathrm{V}_{\mathrm{OC}}$ from 15-20 wt.\% of MWCNTs doping with the sol-gel samples is most likely due to a significant portion of the dye molecules that are either forming aggregates, or are located on the MWCNTs instead of the titania, thus decreasing the amount of light that is effectively converted. With the CVD samples, similar reasons are most likely responsible for the increase in $\mathrm{V}_{\mathrm{OC}}$ from 5-15 wt.\% of MWCNTs and the decrease at $20 \mathrm{wt} . \%$. However, the difference in terms of the sol-gel samples peaking at $10 \mathrm{wt} . \%$ and the CVD samples peaking at 15 wt.\% of MWCNTs doping is due to the morphological differences observed by SEM. The values obtained with the various 5-15 wt.\% of MWCNTs doping samples indicate the nanocomposites can improve device potential significantly.

The results show that $\mathrm{V}_{\mathrm{OC}}$ and the overall efficiencies increased with addition of MWCNTs up to a certain optimum wt.\% loading with the samples synthesized using sol-gel or CVD methods. However, the changes with $\mathrm{J}_{\mathrm{SC}}$ and $\mathrm{FF}$ did not show a consistent trend or correlation. The most probable cause is the fact that overall efficiency of a device is a complex phenomenon influenced by numerous parameters such as layering and distribution of the dye molecules, absorption efficiency, exciton dissociation efficiency, charge carrier lifetime, recombination rates, charge transfer efficiency and charge carrier collection efficiency. ${ }^{56-58}$ This suggests even though high $\mathrm{V}_{\mathrm{OC}}$ may indicate a promising device, there are still various inefficiencies at various interfaces that may result in reduced $\mathrm{FF}$ and $\mathrm{J}_{\mathrm{SC}}$. Since each wt.\% loading will have different physicochemical properties, together with band gap offset in relation with dye used, that interacts in a complex way.

Similar studies with better efficiencies and FF have been reported (Table 4). Key differences include the use of a nonmetal dye with the nanocomposites in this study, use of ITO glass instead of FTO glass, and the use of a non Pt counter electrode. However, the current study has shown that MWCNTs can produce an effective device using non-ideal materials, and comparable $\mathrm{V}_{\mathrm{OC}}$ and $\mathrm{J}_{\mathrm{SC}}$ values which indicates scope for further investigations.

The optimum wt.\% of MWCNTs with the nanocomposites in the DSSCs using Eosin B was 10 and 15 wt.\% for sol-gel and CVD methods, respectively. For comparative purposes, the light-harvesting capabilities of these nanocomposites were tested with the N3-dye (cis-bis(isothiocyanato)bis(2, 2'-bipyridyl-4, 4'-dicarboxylato)ruthenium(II) dye), and the results are presented in Table 5.

A similar trend was observed with the N3-dye in terms of the differences with the sol-gel and CVD samples. The $\mathrm{J}_{\mathrm{SC}}$ values for the sol-gel samples were lower than the CVD samples and can be attributed to the same key parameters outlined above when scrutinizing the results with Eosin B. In terms of loading, the 10 wt.\% MWCNTs nanocomposites synthesized using the CVD method had a better fill factor and slightly improved efficiency when compared to titania without MWCNTs. An interesting aspect when comparing Tables 4 and 5 is that the expensive N3 dye is ideal for pure titania; however, the cheaper Eosin B dye is much more effective with the nanocomposites. This suggests that the photosensitized Eosin B is more effective in transferring electrons into the conduction band of the nanocomposites, and thus the use of such nanocomposites may be beneficial with cheaper dyes or new natural dyes.

\section{Conclusions}

Using a sol-gel and a CVD method MWCNTs were coated with titania. The sol-gel method used a surfactant free method to produce uniformly coated MWCNTs nanocomposites, while the CVD method had a variable morphology with bundles and individual nanotubes coated. The titania was bound to the nanotube walls, and covered defect sites along the nanotube walls. In general, the defect density on the nanotubes differed between the samples synthesized using the sol-gel and CVD methods, with a smaller defect density observed for the latter. FTIR, Raman and XRD analyses confirmed the titania was in the anatase phase for both synthesis methods. The sol-gel samples had a larger surface area and smaller crystallite sizes when compared to the CVD samples. DSSC devices assembled using nanocomposites produced by both methods showed that the CVD samples were generally more efficient. However, all samples produced devices with low efficiencies. In terms of $\mathrm{V}_{\mathrm{OC}}$ and $\mathrm{J}_{\mathrm{SC}}$ values, the devices were comparable to other reports in the literature, and do indicate these nanocomposites can be further investigated for more optimum DSSC architectures.

The use of Eosin B compared to the more expensive N3-dye did show that these types of nanocomposites may be a promising avenue of research in terms of using cheaper and other natural dyes which could reduce the overall price of DSSCs and improve their environmental compatibility. 


\section{Acknowledgements}

The authors wish to thank the University of KwaZulu-Natal, the National Research Foundation (NRF) and the India, Brazil and South Africa (IBSA) Nanomaterials Initiative collaborations for funding this study. The authors acknowledge and thank Prof. Genene Mola for access to the solar simulator instrument.

\section{References}

1 A. Hagfeldt, G. Boschloo, L. Sun, L. Kloo and H. Pettersson, Dye-sensitized solar cells, Chem. Rev., 2010, 110, 6595-6663.

2 M. Grätzel, Dye-sensitized solar cells, J. Photochem. Photobiol., C, 2003, 4, 145-153.

3 R.D. Costa, F. Lodermeyer, R. Casillas and D.M. Guldi, Recent advances in multifunctional nanocarbons used in dye-sensitized solar cells, Energy Environ. Sci., 2014, 7, 1281-1296.

4 M.M. López Guerrero, E. Vereda Alonso, A. Garcíade Torres, M. López Claros and J.M. Cano Pavón, Multivariate optimization of the synthesis of titania biomorphic ceramics and development of a FT-IR method for quantification synthesis yield, Ceram. Int., 2013, 39, 7861-7867.

5 M. Akagi, S. Yanagida and A. Yasumori, Fabrication of LSPR sensor using porous titania-glass composite loading $\mathrm{Au}$ nanoparticles by photocatalytic deposition method, Procedia Eng., 2012, 36, 154-159.

6 C. Dwivedi, N. Raje, J. Nuwad, M. Kumar and P.N. Bajaj, Synthesis and characterisation of mesoporous titania microspheres and their applications, Chem. Eng. J. (Amsterdam, Neth.), 2012, 193-194, 178-186.

7 G.B. Ekoko, J.K.-K. Lobo, O.M. Mvele, A.K. Mbongo, J.L. Muswema and C. Z. Lefuni, Optimization of experimental parameters in preparing multinanoporous $\mathrm{TiO}_{2}$ thin films by the anodic oxidation method, S. Afr. J. Chem., 2013, 66, 1-6.

8 Y. Koo, R. Malik, N. Alvarez, V.N. Shanov, M. Schulz, J. Sankar and Y. Yun, Free-standing carbon nanotube-titania photoactive sheets, J. Colloid Interface Sci., 2015, 448, 148-155.

9 K. Hata, H. Morisaka, K. Hara, J. Mima, N. Yumoto, Y. Tatsu, M. Furuno, N. Ishizuka and M. Ueda, Two-dimensional HPLC on-line analysis of phosphopeptides using titania and monolithic columns, Anal. Biochem., 2006, 350, 292-297.

10 A. de Morais, L.M.D. Loiola, J.E. Benedetti, A.S. Gonçalves, C.A.O Avellaneda, J.H. Clerici, M.A. Cotta and A.F. Nogueira, Enhancing in the performance of dye-sensitized solar cells by the incorporation of functionalized multi-walled carbon nanotubes into $\mathrm{TiO}_{2}$ films: the role of MWCNT addition, J. Photochem. Photobiol., A, 2013, 251, 78-84.

11 Z. Németh, C. Dieker, Á. Kukovecz, D. Alexander, L. Forró, J.W. Seo and K. Hernadi, Preparation of homogeneous titania coating on the surface of MWNT, Compos. Sci. Technol., 2011, 71, 87-94.

12 P.M. Masipa, T. Magadzu and B. Mkhondo, Decoration of multiwalled carbon nanotubes by metal nanoparticles and metal oxides using chemical evaporation method, S. Afr. J. Chem., 2013, 66, 173-178.

13 A. Ansón-Casaos, I. Tacchini, A. Unzue and M.T. Martínez, Combined modification of $\mathrm{TiO}_{2}$ photocatalyst with two different carbon forms, Appl. Surf. Sci., 2013, 270, 675-684.

14 Z. Peining, A.S. Nair, Y. Shengyuan, P. Shengiie, N.K. Elumalai and S. Ramakrishna, Rice grain-shaped $\mathrm{TiO}_{2}$-CNT composite - A functional material with a novel morphology for dye-sensitized solar cell, J. Photochem. Photobiol., A, 2012, 231, 9-18.

15 Y. Li, L. Li, C. Li, W. Chen and M. Zeng, Carbon nanotube/titania composites prepared by a micro-emulsion method exhibiting improved photocatalytic activity, Appl. Catal., A, 2012, 427-428, 1-7.

16 G. Jiang, Z. Lin, L. Zhu, Y. Ding and H. Tang, Preparation and photoelectrocatalytic properties of titania/carbon nanotube composite films, Carbon, 2010, 48, 3369-3375.

17 K. Woan, G. Pyrgiotakis and W. Sigmund, Photocatalytic carbonnanotube-titania $\mathrm{TiO}_{2}$ composites, Adv. Mater. (Weinheim, Ger., 2009, 21, 2233-2239.

18 B. Gao, C. Peng, G.Z. Chen and G. Li Puma, Photo-electro-catalysis enhancement on carbon nanotubes/titanium dioxide $\left(\mathrm{CNTs} / \mathrm{TiO}_{2}\right)$ composite prepared by a novel surfactant wrapping sol-gel method, Appl. Catal., B, 2008, 85, 17-23.

19 G. An, W. Ma, Z. Sun, Z. Liu, B. Han, S. Miao, Z. Miao and K. Ding Preparation of titania/carbon nanotube composites using supercritical ethanol and their photocatalytic activity for phenol degradation under visible light irradation, Carbon, 2007, 45, 1795-1801.
20 N.G. Akalework, C.-J. Pan, W.-N. Su, J. Rick, M.-C. Tsai, J.-F. Lee, J.-M. Lin, L.-D. Tsai and B.-J. Hwang, Ultrathin $\mathrm{TiO}_{2}$-coated MWCNTs with excellent conductivity and SMSI nature as Pt catalyst support for oxygen reduction reaction in PEMFCs, J. Mater. Chem., 2012, 22, 20977-20985.

21 J. Liu, H. Feng, J. Jiang, D. Qian, J. Li, S. Peng and Y. Liu, Anatase$\mathrm{TiO}_{2} / \mathrm{CNTs}$ nanocomposites as 21 a superior high-rate anode for lithium-ion batteries, J. Alloys Compd., 2014, 603, 144-148.

22 H. Abdullah, M.Z. Razali, S. Shaari and M. Raihan Taha, Manipulation of MWCNT concentration in $\mathrm{MWCNT} / \mathrm{TiO}_{2}$ nanocomposite thin films for dye-sensitized solar cell, Int. J. Photoenergy 9, 2014, 2014, 9.

23 P. Du, L. Song, J. Xiong, N. Li, L. Wang, Z. Xi, N. Wang, L. Gao and $\mathrm{H}$. Zhu, Dye-sensitised solar cells based on anatase $\mathrm{TiO}_{2}$ multiwalled carbon nanotubes composite nanofibers photoanode, Electrochim. Acta, 2013, 87, 651-656.

24 M. F.L. De Volder, S.H. Tawfick, R.H. Baughman and A.J. Hart, Carbon Nanotubes: Present and Future Commercial Applications, Science, 2013, 339, 535-539.

25 S. Hwang, J. Moon, S. Lee, D.H. Kim, D. Lee, W. Choi and M. Jeon, Carbon nanotubes as counter electrode for dye-sensitised solar cells, Electron. Lett., 2007, 43, 1455-1456.

26 H. Usui, H. Matsui, N. Tanabe and S. Yanagida, Improved dye-sensitised solar cells using ionic nanocomposite gel electrolytes, J. Photochem. Photobiol., A, 2004, 164, 97-101.

27 S. Kim, S.-R. Jang, R. Vittal, J. Lee and K.-J. Kim, Rutile $\mathrm{TiO}_{2}$-modified multi-wall carbon nanotubes in $\mathrm{TiO}_{2}$ film electrodes for dyesensitized solar cells, J. Appl. Electrochem., 2006, 36, 1433-1439.

28 K.-M. Lee, C.-W. Hu, H.-W. Chen and K.-C. Ho, Incorporating carbon nanotube in a low-temperature fabrication process in a $\mathrm{TiO}_{2}$ dyesensitized solar cells, Sol. Energy Mater. Sol. Cells, 2008, 92, 1628-1633.

29 T.Y. Lee, P.S. Alegaonkar and J.-B. Yoo, Fabrication of dye sensitised solar cells using $\mathrm{TiO}_{2}$ coated carbon nanotubes, Thin Solid Films, 2007, 515, 5131-5135.

30 M. Sánchez and M.E. Rincón, Sensor response of sol-gel multiwalled carbon nanotubes- $\mathrm{TiO}_{2}$ composites deposited by screen-printing and dip-coating techniques, Sens. Actuators, B, 2009, 140, 17-23.

31 A. R. Boccaccini, J. Cho, T. Subhani, C. Kaya and F. Kaya, Electrophoretic deposition of carbon nanotube-ceramic nanocomposites, J. Eur. Ceram. Soc., 2010, 30, 1115-1129.

32 G. Fang, W. Gao, Q. Deng, K. Qian, H. Han and S. Wang, Highly selective capture of phosphopeptides using a nano titanium dioxidemultiwalled carbon nanotube nanocomposite, Anal. Biochem., 2012, 423, 210-217.

33 N. Hintsho, L. Petrik, A. Nechaev, S. Titinchi and P. Ndungu, Photocatalytic activity of titania dioxide carbon nano-tube nanocomposites modified with silver and palladium nanoparticles, Appl. Catal., B, 2014, 156-157, 273-283.

34 B. Gao, G.Z. Chen and G. Li Puma, Carbon nanotubes/titanium dioxide $\left(\mathrm{CNTs} / \mathrm{TiO}_{2}\right)$ nanocomposites prepared by conventional and novel surfactant wrapping sol-gel methods exhibiting enhanced photocatalytic activity, Appl. Catal., B, 2009, 89, 503-509.

35 J.-Y. Lin, W.-Y. Wang and S.-W. Chou, Flexible carbon nanotube/polypropylene composite plate decorated with (3,4-ethylenedioxythiophene) as efficient counter electrodes for dye-sensitized solar cell, J. Power Sources, 2015, 282, 348-357.

36 I.K. Ding, J. Melas-Kyriazi, N.-L. Cevey-Ha, K.G. Chittibabu, S.M. Zakeeruddin, M. Grätzel and M.D. McGehee, Deposition of hole transport materials in solid-state dye-sensitised solar cells by doctorblading, Org. Electron., 2010, 11, 1217-1222.

$37 \mathrm{H}$. Gerischer, Charge transfer processes at semiconductor-electrolyte interfaces in connection with problems of catalysis, Surf. Sci.,1969, 18, $97-122$.

38 C.C. Mercado, F.J. Knorr, J.L. McHale, S.M. Usmani, A.S. Ichimura and L.V. Saraf, Location of hole and electron traps on nanocrystalline anatase $\mathrm{TiO}_{2}$, J. Phys. Chem. C, 2012, 116, 10796-10804.

39 D. Zhao, X. Yang, C. Chen and X. Wang, Enhanced photocatalytic degradation of methylene blue on multiwalled carbon nanotubes$\mathrm{TiO}_{2}$, J. Colloid Interface Sci., 2013, 398, 234-239.

40 M. Radoičić, Z. Šaponjić, J. Nedeljković, G. Cirić-Marjanović and J. Stejskal, Self-assembled polyaniline nanotubes and nanoribbons/titanium dioxide nanocomposites, Synth. Met., 2010, 160, 1325-1334.

41 S.A. Kosa, G. Al-Zhrani and M. Abdel Salam, Removal of heavy 
metals from aqueous solutions by multi-walled carbon nanotubes modified with 8-hydroxyquinoline, Chem. Eng., 2012, 181-182, 159-168.

42 N. V. Qui, P. Scholz, T. Krech, T.F. Keller, K. Pollok and B. Ondruschka, Multiwalled carbon nanotubes oxidised by UV/ $\mathrm{H}_{2} \mathrm{O}_{2}$ as catalyst for oxidative dehydrogenation of ethylbenzene, Catal. Comm., 2011, 12, 464-469.

43 J.H. Lehman, M. Terrones, E. Mansfield, K.E. Hurst and V. Meunier, Evaluating the characteristics of multiwall carbon nanotubes, Carbon, 2011, 49, 2581-2602.

44 Y. Li, L. Li, C. Li, W. Chen and M. Zeng, Carbon nanotube/titania composites prepared by a micro-emulsion method exhibiting improved photocatalytic activity, Appl. Catal., A, 2012, 427-428, 1-7.

45 M. Sánchez and M.E. Rincón, Effect of multiwalled carbon nanotube functionalization on the gas sensing properties of carbon nanotubetitanium dioxide hybrid materials, Diamond Relat. Mater., 2012, 21, $1-6$.

46 S. Osswald, M. Havel and Y. Gogotsi, Monitoring oxidation of multiwalled carbon nanotubes by Raman spectroscopy, J. Raman Spectrosc., 2007, 38, 728-736.

47 S. Wang and S. Zhou, Photodegradation of methyl orange by photocatalyst of $\mathrm{CNTs} / \mathrm{P}-\mathrm{TiO}_{2}$ under $\mathrm{UV}$ and visible-light irradiation, J. Hazard. Mater., 2011, 185, 77-85.

48 P. Delhaes, M. Couzi, M. Trinquecoste, J. Dentzer, H. Hamidou and C. Vix-Guterl, A comparison between Raman spectroscopy and surface characterization of a multiwall carbon nanotubes, Carbon, 2006, 44, 3005-3013.

49 Y. Ando, X. Zhao and H. Shimoyama, Structure analysis of purified multiwalled carbon nanotubes, Carbon, 2001, 39, 569-574.

50 T. Belin and F. Epron, Characterization methods of carbon nanotubes: a review, Mater. Sci. Eng., B, 2005, 119, 105-118.

51 J. Marugán, M.-J. López-Muñoz, J. Aguado and R. van Grieken, On the comparison of photocatalysts activity: a novel procedure for the measurement of titania surface in $\mathrm{TiO}_{2} / \mathrm{SiO}_{2}$ materials, Catal. Today, 2007, 124, 103-109.

52 M.R. Golobostanfard and H. Abdizadeh, Hierarchical sol-gel derived porous titania/carbon nanotube films prepared by controlled phase separation, Microporous Mesoporous Mater., 2014, 183, 74-80.

53 K. S.W. Sing, A new analysis method for the determination of the pore size distribution of porous carbons from nitrogen adsorption measurements, Int. J. Pure Appl. Chem., 1985, vol. 57, p. 603.

54 D. Zhao, X. Yang, C. Chen and X. Wang, Enhanced photocatalytic degradation of methylene blue on multiwalled carbon nanotubes$\mathrm{TiO}_{2}$, J. Colloid Interface Sci., 2013, 398, 234-239.

5\$. Villanueva-Cab, S.-R. Jang, A.F. Halverson, K. Zhu and A.J. Frank, Trap-free transport in ordered and disordered $\mathrm{TiO}_{2}$ nanostructures, Nano Lett., 2014, 14, 2305-2309.

56 J. Chen, T. Peng, K. Fan, R. Li and J. Xia, Optimization of plastic crystal ionic liquid electrolyte for solid-state dye-sensitized solar cell, Electrochim. Acta, 2013, 94, 1-6.

57 Q. Wang, S. Ito, M. Grätzel, F. Fabregat-Santiago, I. n. Mora-Sero, J. Bisquert, T. Bessho and H. Imai, Characteristics of high efficiency dye-sensitized solar cells, J. Phys. Chem. B, 2006, 110, 25210-25221.

58 J. Sobuś, J. Karolczak, D. Komar, J.A. Anta and M. Ziółek, Transient states and the role of excited states self-quenching of indoline dyes in complete dye-sensitized solar cells, Dyes Pigm., 2015, 113, 692-701 